\title{
Qualification testing of an innovative system for monitoring particle contamination fallout \\ I.Tovena Pecault ${ }^{1}$, P.Godefroy ${ }^{2}$, L.Escoubas ${ }^{3}$
}

${ }^{1}$ CEA CESTA, Bât.692, 33116 LE BARP, isabelle.tovena-pecault@cea.fr

\section{$\underline{\text { (Corresponding author) }}$}

${ }^{2}$ Winlight System, 135 Rue Benjamin Franklin, ZA Saint Martin, 84120 PERTUIS

${ }^{3}$ Aix-Marseille University - IM2NP, CNRS (UMR 7334), France

\begin{abstract}
Isabelle Tovena Pecault was graduated from Polytech Montpellier as an engineer in materials science. She obtained her PhD in materials science in 1995. At CEA, she has been working for 10 years on the long term behaviour of nuclear waste and for 14 years in the Laser Mega Joule frame as the cleanliness manager. She is involved in the international standardization on cleanrooms and controlled environment. She has written two books, 10 patents and more than 100 of papers and communications.
\end{abstract}

Philippe Godefroy (45 years old) was graduated from Centrale Marseille (a French "Grande Ecole" of Engineer). He has intensively worked in the field of optomechanics and high performance optics manufacturing since and he has founded WINLIGHT SYSTEM company in 2001. He has founded two new companies WINLIGHT OPTICS and WINLIGHT $X$ since. The core business of the three companies is the study and manufacturing of complex optical systems and components for the fields of Space, Astronomy, Defence and Sciences. He has authored more than 10 papers and communications and holds 4 patents.

Ludovic Escoubas (44 years old) was graduated from Centrale Marseille (a French "Grande Ecole" of Engineer), and received a PhD in Optics in 1997. He is now Professor at Aix-Marseille University (AMU), director of the doctoral school "Sciences pour l'Ingénieur" at AMU, and researcher in the OPTO-PV Team (" Optoelectronics Components and Photovoltaics") of IM2NP (CNRS Laboratory). His current research interests are photovoltaics and photonics. He has authored more than 250 papers and communications and hold 11 patents.

\begin{abstract}
Particle fallout in cleanrooms is a primary concern for industries manufacturing critical products with surfaces highly susceptible to particulate contamination. Limited research has been conducted to measure the deposited particles in cleanroom. In the frame of the ISO 14644-3, this paper compares the traditional technique for particle fallout measurements using witness plates to a real-time and in situ measurement done by an innovative device: CLEAPART-100. The CLEAPART-100 detects the same contamination event as optical counters detect. The comparison with the settle plates observed under a microscope shows the loss of particles using that indirect measurement which is unacceptable for an accurate risk analysis assessment.
\end{abstract}

Keywords : particulate contamination, real-time device, cleanroom 


\section{Introduction}

Particle fallout in cleanrooms is a primary concern for industries manufacturing critical products with surfaces highly susceptible to particulate contamination $[1,2,3]$. As an example, particulate contaminants can be hazardous to spacecraft in a number of ways including failure of precision mechanisms, light absorption and scattering, points of high local electric field and associated electrostatic discharge, and noise on electrical contacts.

Till the 1970's, many studies were done on the particle fall out distribution modelling in cleanrooms $[4,5,6,7,8]$. It was concluded that the size distribution of particles on surfaces exposed to fall out in cleanroom was quite difficult to predict. It was highly recommended to measure very accurately those critical particles near the critical surfaces [9].

The objective of the ECSS-Q-70-50-C standard [10], as an example, was to ensure that the particle monitoring of spacecraft systems and cleanrooms utilised in the production of such systems, was carried out in an appropriate manner, and was controlled both in terms of the precision of the measurements and the reproducibility of such measurements.

The ISO 14644-3: 2005 standard [11](in the annex dealing with particle deposition testing) describes the procedures and methods to be used to measure and count particles which have been or may be deposited from the air onto the work surfaces or products inside cleanrooms. Deposited particles are collected on suitable witness plates, similar to the surfaces considered to be at-risk, and the size and number of these particles are analysed using an optical microscope, an electron microscope or other surface analysis equipment. In 2015, the standard was revised in response to the growing preoccupation of industrial operators regarding this form of contamination risk, and Annex B.11 dealing with particle deposition tests has been considerably expanded. The traditional technique of using witness plates to collect particles and then analysing them with a microscope or photometer may now be replaced by instruments capable of monitoring particle deposition in real time [11]. Instruments already available on the market include the PDM (Particle Deposition Meter) developed by SAC and the APMON unit from TNO [12, 13]. However, none of these instruments is equipped to provide real-time measurements of particles as small as $5 \mu \mathrm{m}$, and on surfaces large enough to be considered statistically representative. Notice that $5 \mu \mathrm{m}$ particles are the limits for the airborne particle cleanliness classification according to ISO 14644-1[14]. That is why it is important to complete airborne particles measurement done by optical counter with deposited particles measurement till $5 \mu \mathrm{m}$.It was this lack of satisfactory equipment that first inspired CEA-CESTA to join forces with the University of Aix-Marseille and Winlight Systems to develop the DELCO, now renamed the CLEAPART-100 v1 [15]. This paper summarises the results of some of the qualification tests CEA-CESTA conducted on the CLEAPART-100 v1 at the MegaJoule Laser facility in 2014-2015.

\section{Materials and Methods}

The CLEAPART-100 is an innovative system for counting deposited particles and monitoring the cleanliness of controlled environments. It allows users to detect particles and sort them by size, starting from $5 \mu \mathrm{m}$. The CLEAPART-100 was developed by Winlight Systems in partnership with CEA and the University of Aix-Marseille since 2012 [16].

The detector comes in cube form, suitable for cleanroom use. It has a high flatness glass surface $\left(100 \mathrm{~cm}^{2}\right.$ surface) which collects particles, which are then detected by a mobile optical camera positioned underneath the glass plate, on $\mathrm{X}$ and $\mathrm{Y}$ axes (cf. Figure 1). 


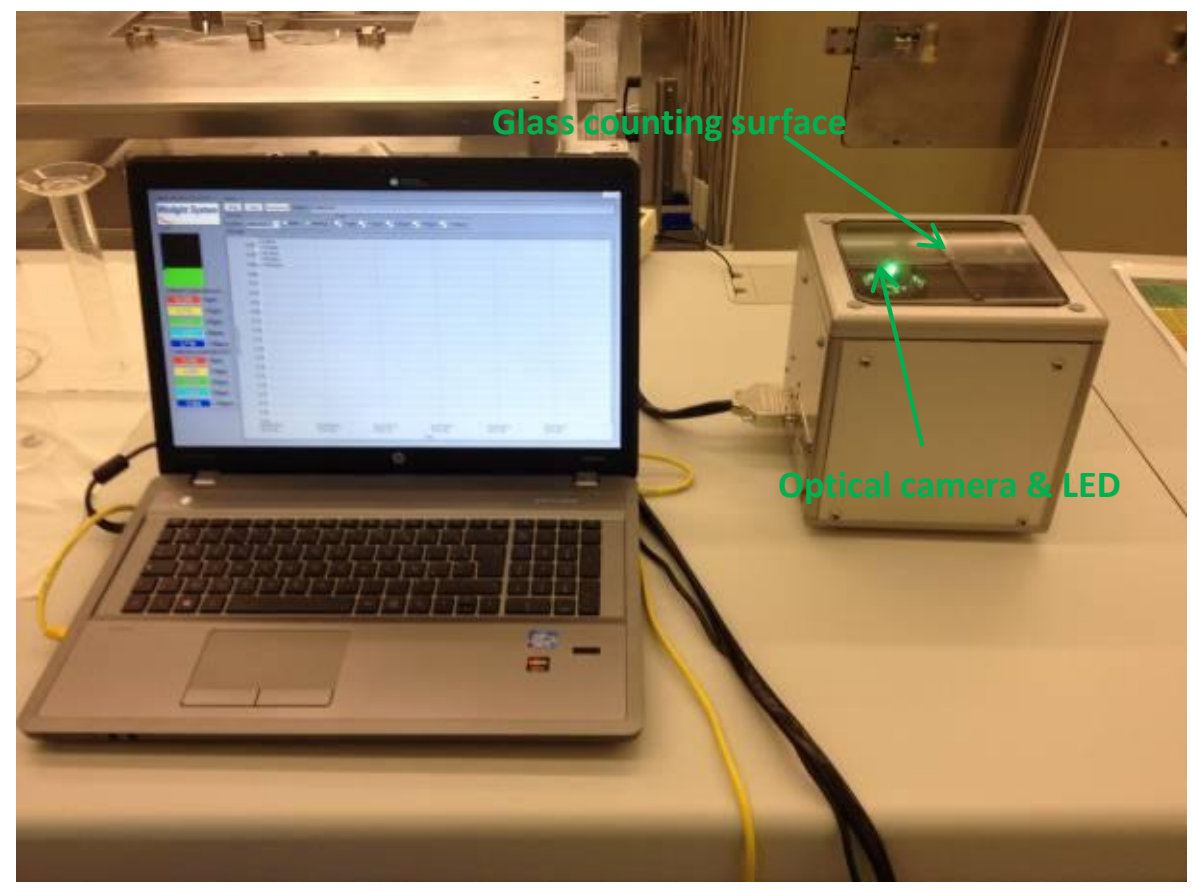

\section{Figure 1. Computer + CLEAPART-100}

The principle is simple: the high-resolution camera scans the reference surface (cf. Fig. 2).

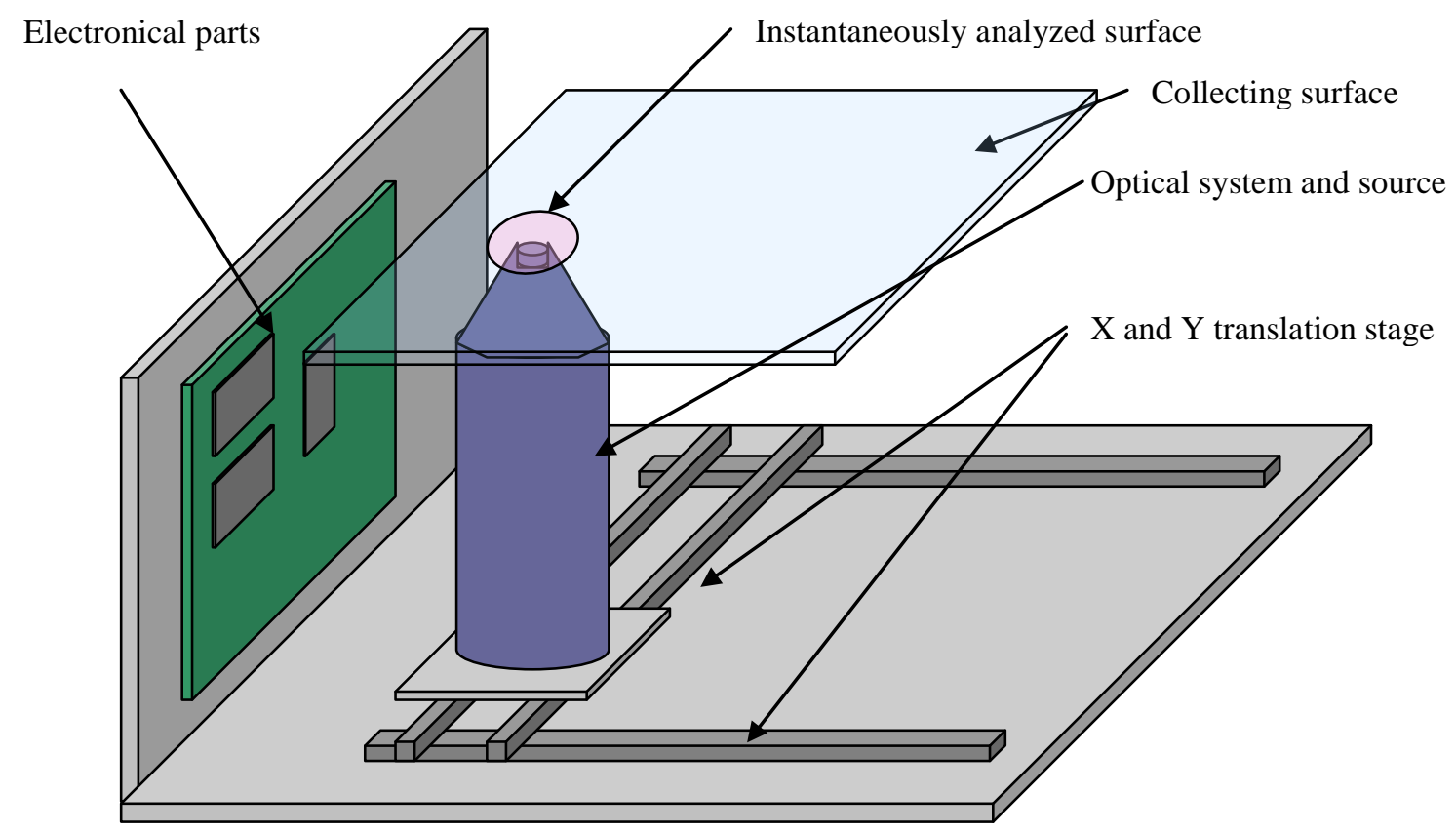

\section{Figure 2. Scheme of the CLEAPART - 100 system}

The system is working in dark-field. Indeed, the particles deposited on the glass surface are illuminated in oblique incidence using green leds. Then the light scattered back by the particles is collected and a specific designed zoom lens allows an image to be obtained on the camera (cf. Fig 3). The inclination of the leds is adjusted to avoid any specular reflected light to enter into the zoom lens (principle of dark field imaging). The zoom lens is designed to allow a high aperture to be reached enabling a resolution in the image better than 5 microns in 
a $6 \mathrm{~mm}$ large field. The zoom lens also includes an optical filter to reach a better signal to noise ratio.

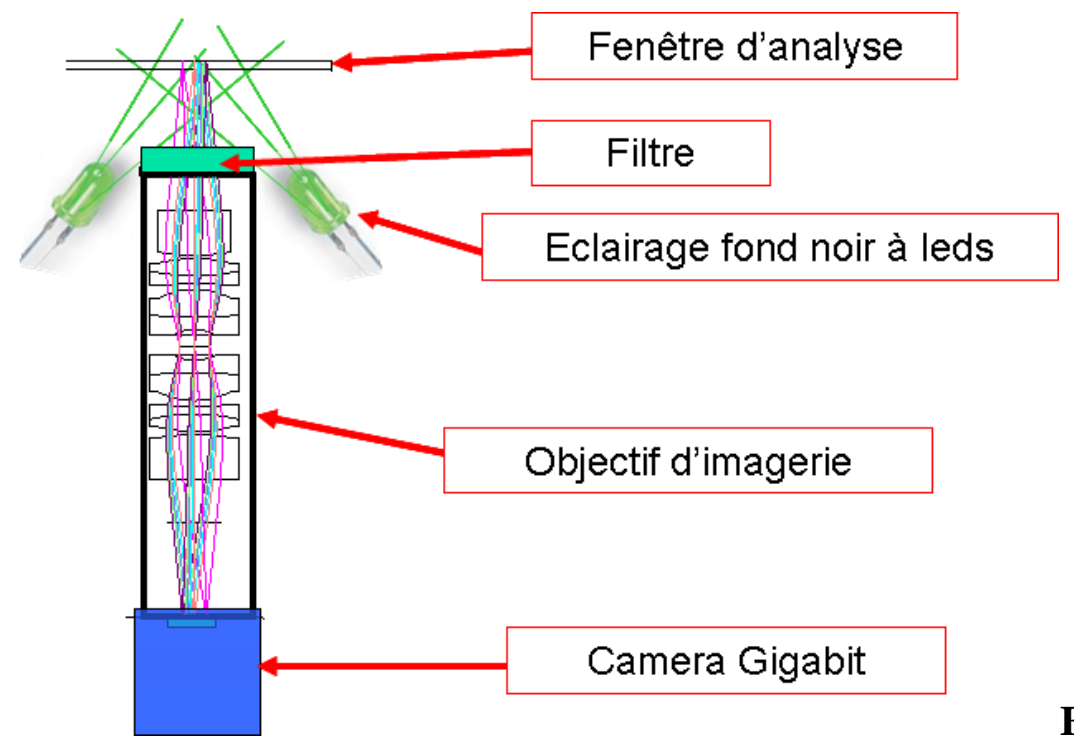

the CLEAPART - 100

Figure 3. Optical system of

The camera is a megapixel optical sensor (4x5 $\mathrm{mm}^{2}$ surface and 5 microns resolution) including a gigabit connection.

The measuring period lasts for 5 minutes, and can be repeated continuously for several days.

The images of the detected particles are visible on the computer screen (cf. Fig. 4) and specific software has been developed to allow a classification of the particles by size to be obtained. In its first incarnation, the CLEAPART-100 was piloted from an external PC (cf. Fig. 1); v2.0 is autonomous, which means that it is no longer necessary to bring an additional computer into the cleanroom. Particles detected and imaged on Figure 4 are counted and sorted by size. The results represent the surface density of particles, sorted by size from $5 \mu \mathrm{m}$ upwards. This density is monitored over time, allowing for the detection of contamination incidents. 


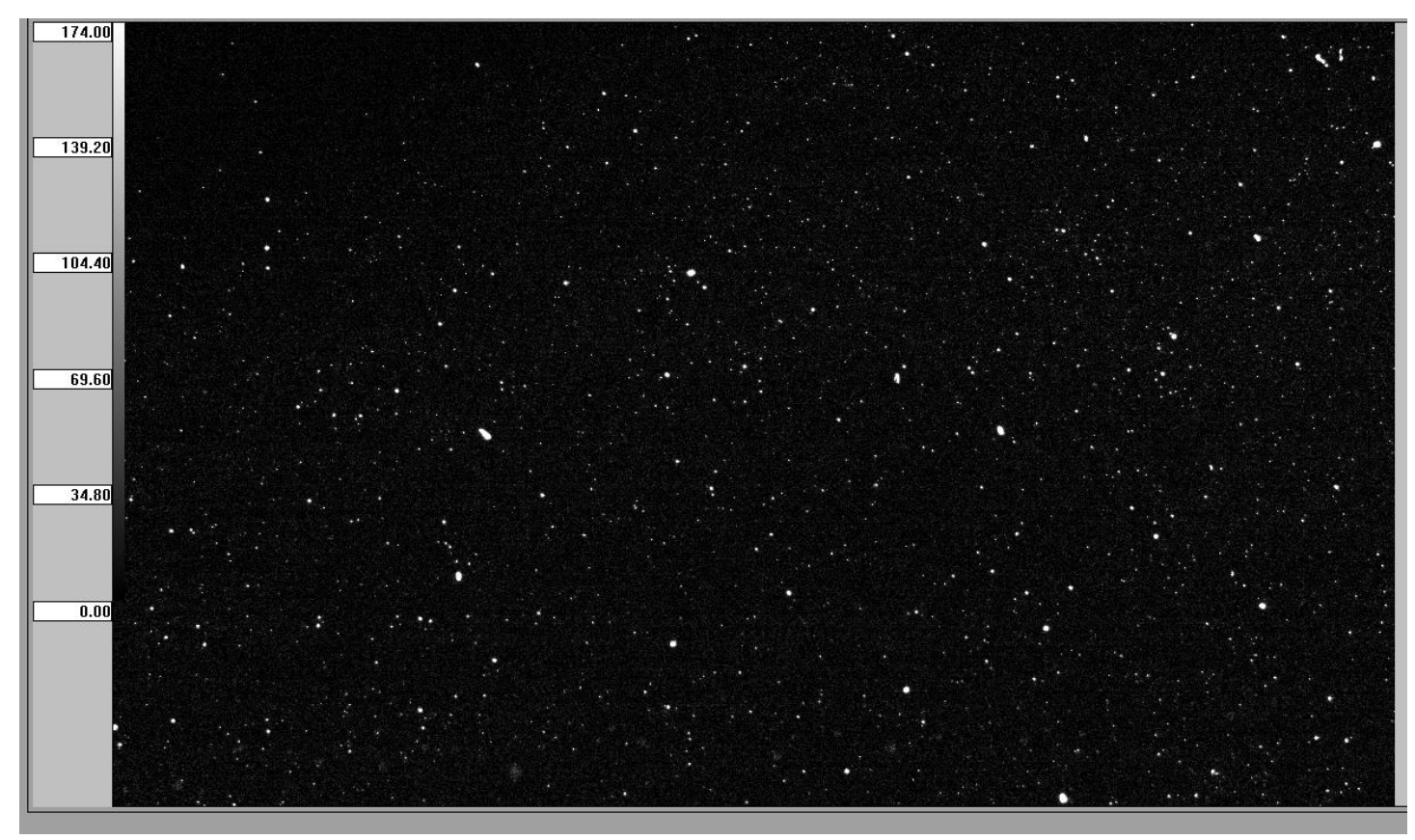

\section{Figure 4. Example of particle image obtained using the CLEAPART - 100}

This paper gives an overview of the qualification testing conducted on the CLEAPART-100 v1 by CEA-CESTA in 2014-2015. The goal was to compare the results obtained from the CLEAPART-100 with those from other deposition targets (polycarbonate membranes and glass microscope slides), and also to check that the CLEAPART-100 detects the same contamination events as those detected by the optical counter. The CLEAPART-100 is piloted by a dedicated laptop computer. The results in terms of number of particles deposited per $\mathrm{cm}^{2}$ are plotted on a graph in real time, sorted by size $(>5,>15,>25,>50,>100 \mu \mathrm{m})$. The CLEAPART-100 is programmed to take one measurement every 30 minutes in this experiment. The counting process lasts for 5 minutes. The uncertainty of the CLEAPART-100 counting has been assessed using a test pattern on the CLEAPART-100 window. The pattern represents a network of thousands of particles $10 \mu \mathrm{m}$ in size. We have then compared the number of particles counted by CLEAPART-100 to the predefined number of particles on the pattern. So doing, the CLEAPART-100 uncertainty is $\pm 1 \%$.

A METONE (flow rate of 2.8321 per minute) optical counter is used to detect aerosol particles measuring $>0.3,>0.5,>0.7,>1,>2$ and $>5 \mu \mathrm{m}$. As with the CLEAPART-100, the optical counter is programmed to take a measurement every 30 minutes. Strictly speaking, only the latter level of precision should be used for the purposes of comparison with the data recorded by the CLEAPART-100: $>5 \mu \mathrm{m}$.

Two different types of deposition targets are used:

- polycarbonate membrane filters from Millipore (Isopore ${ }^{\circledR}$ with a cut-off threshold of $0.2 \mu \mathrm{m}$ ) generally used to monitor particle deposition contamination at the LMJ,

- glass microscope slides used exclusively for this programme in order to obtain a collection surface more representative of the CLEAPART-100's silicate glass plate.

These deposition targets are spray-washed with ethanol and checked with UV lamps and in direct light. A cloth soaked in ethanol is also used to clean the microscope slides. The boxes 
housing the membrane filters and microscope slides, cleaned in advance, are opened to leave the targets exposed. The whole process of preparing these deposition targets is conducted in ISO 5 conditions. Five polycarbonate membrane filters are used for each test. Each membrane measures $12.6 \mathrm{~cm}^{2}$; the 5 membranes therefore present a combined surface area of $63 \mathrm{~cm}^{2}$, not too far off the $100 \mathrm{~cm}^{2}$ collection surface of the CLEAPART-100. At the end of the experiment, each membrane is covered over with its own lid and transported carefully (without tilting) to the laboratory for optical microscope analysis supplemented with the Filtrex ${ }^{\circledR}$ image analysis system (Microvision).The other testing process generally requires three glass microscope slides. Each slide presents a surface area equivalent to that of the polycarbonate membranes, i.e. $12.6 \mathrm{~cm}^{2}$.

Two environments were selected to illustrate the results of this process:

- an ISO 8 clean environment : the test chamber of the MegaJoule Laser during maintenance,

- a dirty environment : an office with carpet floors.

Table 1 details the corresponding test conditions.

Table 1. Test conditions for the CLEAPART-100

\begin{tabular}{|c|c|c|c|c|c|c|}
\hline & $\begin{array}{l}\text { Environment } \\
\text { classification }\end{array}$ & $\begin{array}{l}\text { Duration } \\
\text { (h) }\end{array}$ & $\begin{array}{l}\text { Polycar } \\
\text { bonate } \\
\text { depositi } \\
\text { on } \\
\text { targets }\end{array}$ & $\begin{array}{l}\text { Glass } \\
\text { depositio } \\
\text { n targets }\end{array}$ & $\begin{array}{l}\text { Optic } \\
\text { al } \\
\text { counte } \\
\text { r }\end{array}$ & Comments \\
\hline $\begin{array}{l}\text { SE } \\
\text { LMJ }\end{array}$ & ISO 8 & 21 & 5 & 3 & yes & \\
\hline $\begin{array}{l}\text { Office } \\
\text { - day- } \\
\text { time }\end{array}$ & Unclassified & $4 h$ & 3 & - & yes & $\begin{array}{l}\text { Collection of } \\
\text { particles } \\
\text { deposited on the } \\
\text { glass panel of the } \\
\text { CLEAPART-100 } \\
\text { using } 5 \text { gels, } \\
\text { studied under the } \\
\text { microscope for } \\
\text { comparison with } \\
\text { CLEAPART }\end{array}$ \\
\hline
\end{tabular}




\section{Results and discussion}

CLEAPART-100 is used in calibration mode; an initial scan of the collection surface is conducted. This is the starting state used as the benchmark when counting the number of particles deposited on the surface. This saves time when launching a measuring operation, as it is no longer necessary to clean the CLEAPART-100's collection surface before starting the measurement. In this ISO 8 cleanroom, at the start of this test, the glass surface was already covered with 50 particles $>5 \mu \mathrm{m}$ per $\mathrm{cm}^{2}, 33$ particles $>15 \mu \mathrm{m}$ per $\mathrm{cm}^{2}, 10$ particles $>50 \mu \mathrm{m}$ per $\mathrm{cm}^{2}$ and almost 10 particles $>100 \mu \mathrm{m}$ per $\mathrm{cm}^{2}$ (cf. calibration inset - Figure 5). The uncertainty has been estimated to $\pm 1 \%$.

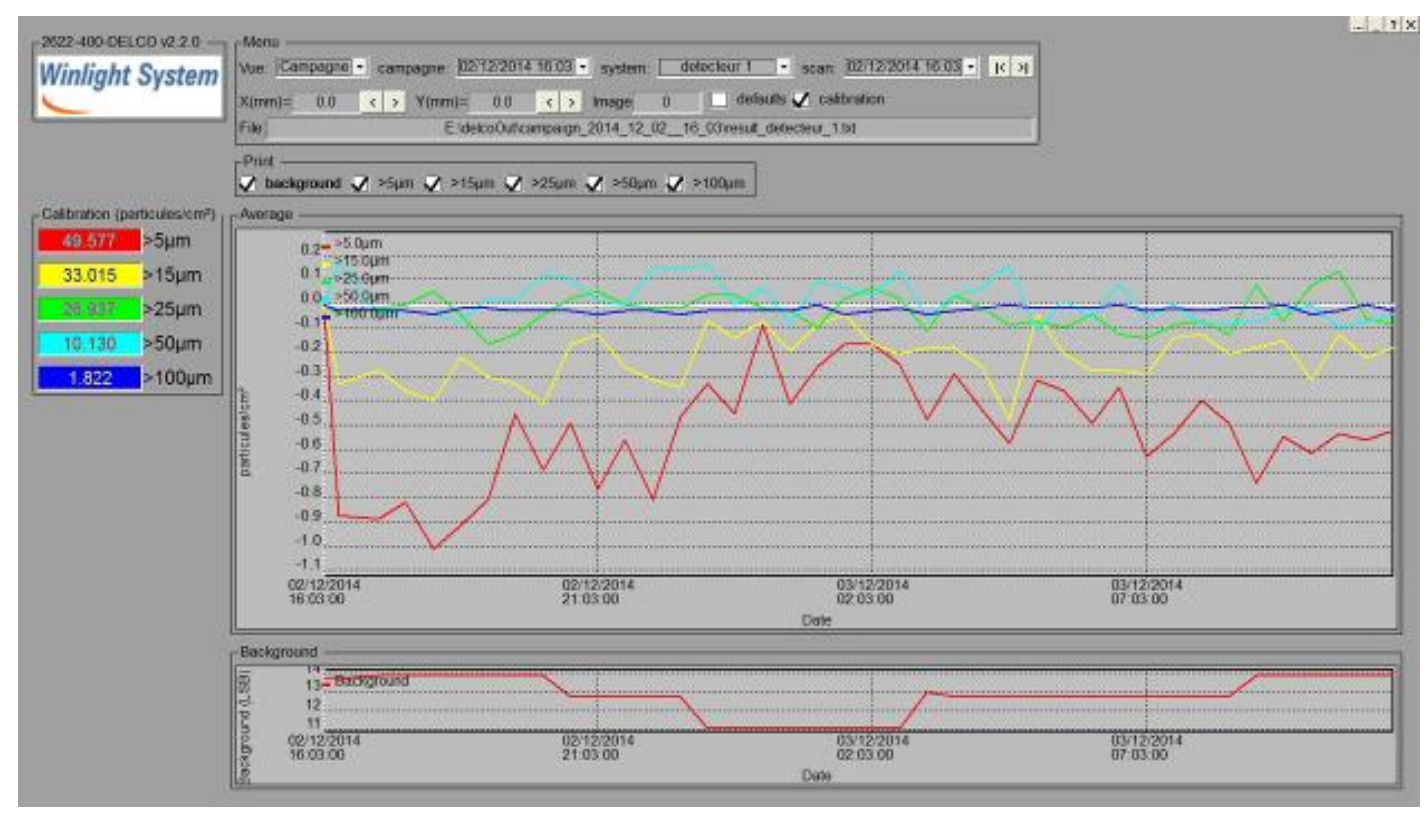

Figure 5. Results for particles counted on the sensor surface of the CLEAPART-100 after calibration (ISO 8 cleanroom).x-axis gives the date in days; $y$-axis gives the number of particles counted in particles $/ \mathrm{cm}^{2}$ after subtraction of the initial particles present on the glass ( Cf. calibration inset)

Irrespective of size $(>5,>15,>25,>50,>100 \mu \mathrm{m})$, few particles were detected during the day. Focusing on particles of size higher than $25 \mu \mathrm{m}$, there appear to be several peaks of contamination: at the start of the test around 9pm on the 2/12, at 2am on 3/12 and towards midday, a few hours before the CLEAPART-100 was stopped. We used an optical counter to analyse 2.83 litre sample of air per minute. We have therefore opted to express our results in terms of particles/litre.

Figure 6 illustrates the aerosol results for one category of particle $(>0.3 \mu \mathrm{m})$ over time. We compare the concentration in part/l of the particules larger than $0.3 \mu \mathrm{m}$ (limit of detection of the optical counter) with the deposition rate measured by the CLEAPART-100 for the smaller particle size $(5 \mu \mathrm{m})$. 


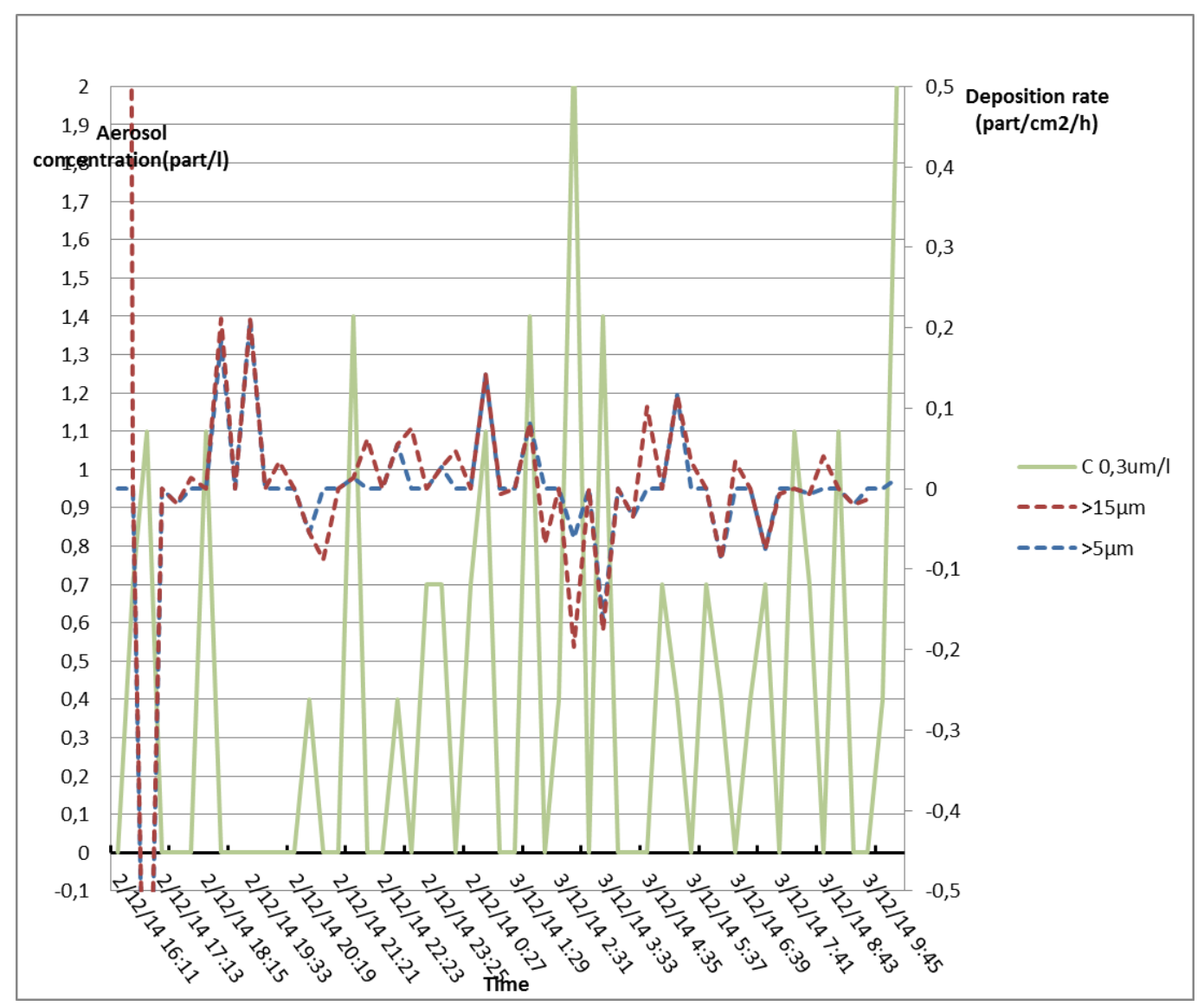

Figure 6. Aerosol count results (ISO 8 cleanroom) compared to deposition rate given by the CLEAPART-100

The graph shows very low contamination levels. Over this period the environment was of ISO 7 or cleaner according to ISO 14644-1. The maximum concentration of aerosol particles larger than $0.3 \mu \mathrm{m}$ detected during the test period was 2.1part/l. Even if the aerosol concentration is very low, there is an oscillating aerosol emission phenomenon which is clearly confirmed by the CLEAPART-100 unit. As can be seen on figure 6, the peaks for CLEAPART-100 deposition rate are very similar to those detected by the optical counter.

The results for the number of particles collected on the glass slides (cf. Figure 7) are compared to those collected on polycarbonate membranes. We consider that the distribution of the results is normal and then the expanded uncertainty is the standard deviation multiplied by a coverage factor of two. The coverage probability is then near $95.5 \%$. These results are then consistent with those measured by the CLEAPART-100: very few particles detected (less than $0.2 \pm 0.04$ part./ $\mathrm{cm}^{2}$ for particles larger than $25 \mu \mathrm{m}-$ see figure 5). 


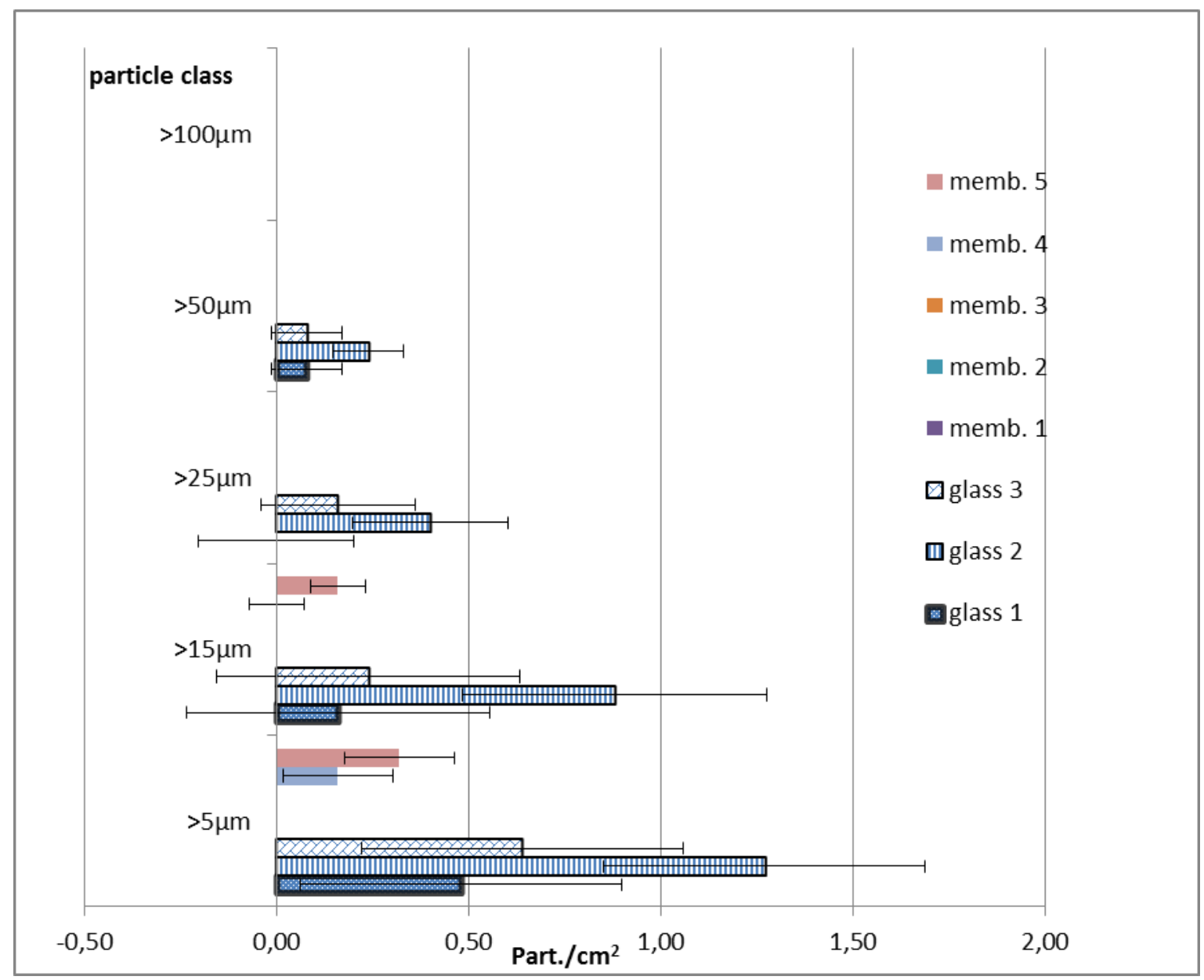

\section{Figure 7. Comparison of the deposited particles counted under the microscope for 5 membranes and three glass slides.}

Notice that fewer particles were detected on the polycarbonate membranes than on the glass slides.

The nature of the deposition targets has thus an influence on the number of particles collected and counted, or on their adhesion to the surface while being transferred to the laboratory for analysis. The number of particles collected on the glass slides is 8 times higher than the number collected on the polycarbonate membranes for the particles larger than $5 \mu \mathrm{m}$ and 13 times higher for particles larger than $15 \mu \mathrm{m}$. This might be due to stronger dispersive adhesion strength on very smooth surfaces as those of glass slides rather than on polycarbonate membranes. Thus, when particles are collected on glass, they adhere to the glass surface, whereas for polycarbonate membranes, the particles might be transferred into the box and thus are not counted when using the optical counter.

To minimise the particles transfer from the collection surface (membrane or glass slide to the transportation box), we decided to collect particles from the glass collection panel of the CLEAPART-100 using gels (gelpack®), gels which would subsequently be analysed using an optical microscope. This would allow for direct comparison of the results from the CLEAPART-100 with those from the gels, these gels allowing us to avoid losing any particles during the process of transporting samples to the laboratory for analysis. The results for 
deposited particles counted on the collecting surface of the CLEAPART-100 - before being removed using gels - are represented on figure 8 .

We then used 3 gels to cover just over a third of the surface of the CLEAPART-100, transferring the particles from the CLEAPART-100 to the surface of the gels.

As shown in figure 8 , the analysis of the 3 polycarbonate membranes once again made it clear that the CLEAPART-100 collects more particles than polycarbonate membranes positioned nearby. Analysis of the gels using an optical microscope in transmission mode gives results very similar to those of the CLEAPART-100 considering their respective uncertainty.

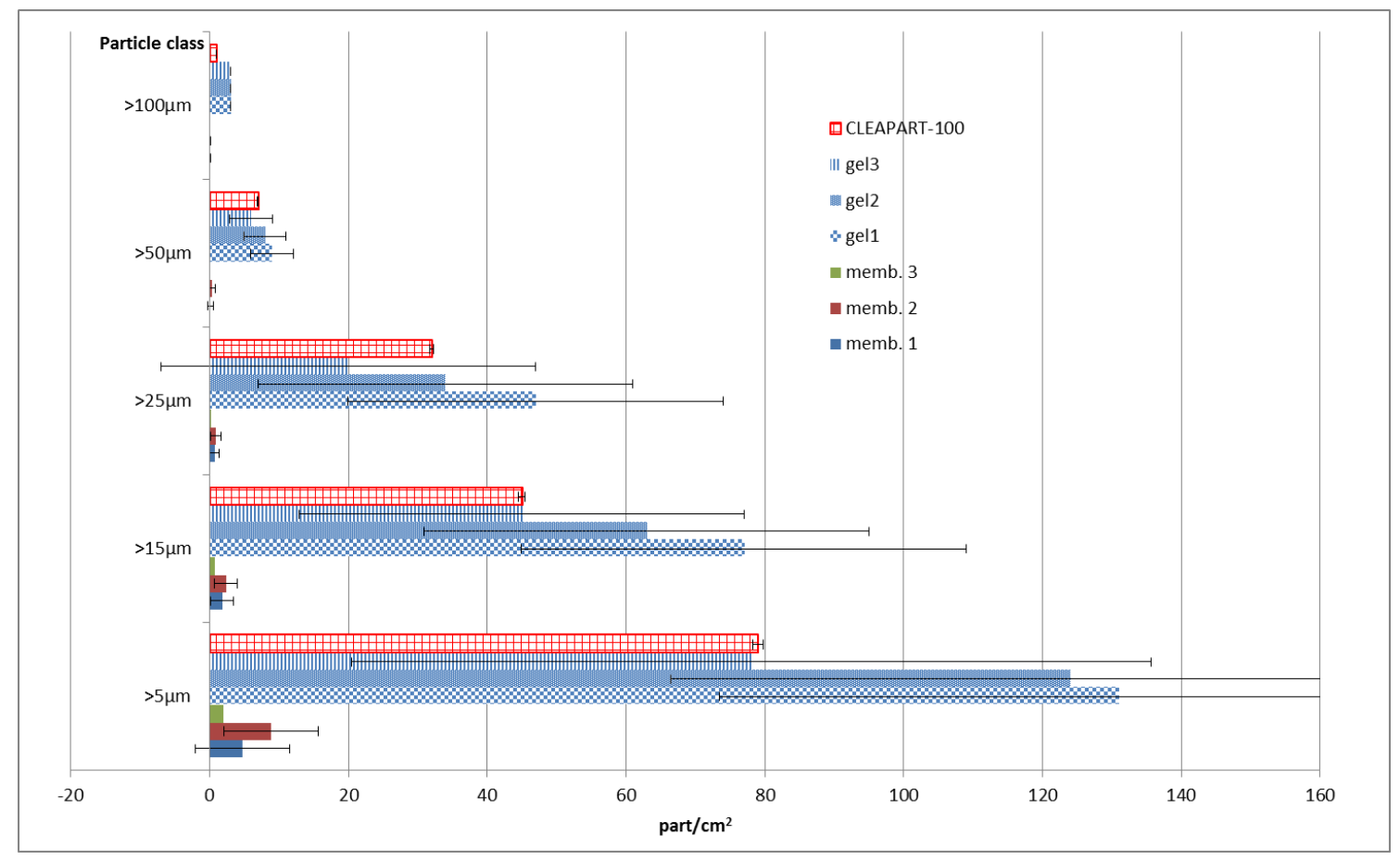

Figure 8. Comparison of the deposited particles counted under the microscope for 3 membranes and 3 gels and the CLEAPART-100 results (office environment)

It thus appears that the results obtained from the CLEAPART-100 are identical to those obtained by analysing the gels (used to collect particles from the surface of the CLEAPART100) using an optical microscope in transmission mode if we consider their associated uncertainty.

If we consider figure 9, one can see that the aerosol counter and CLEAPART-100 detect similar contamination events when comparing the deposition rate given by the CLEAPART100 and the aerosol concentration given by the optical counter. Unfortunately, the aerosol measurements between 12:00 and 13:00 were not registered. 


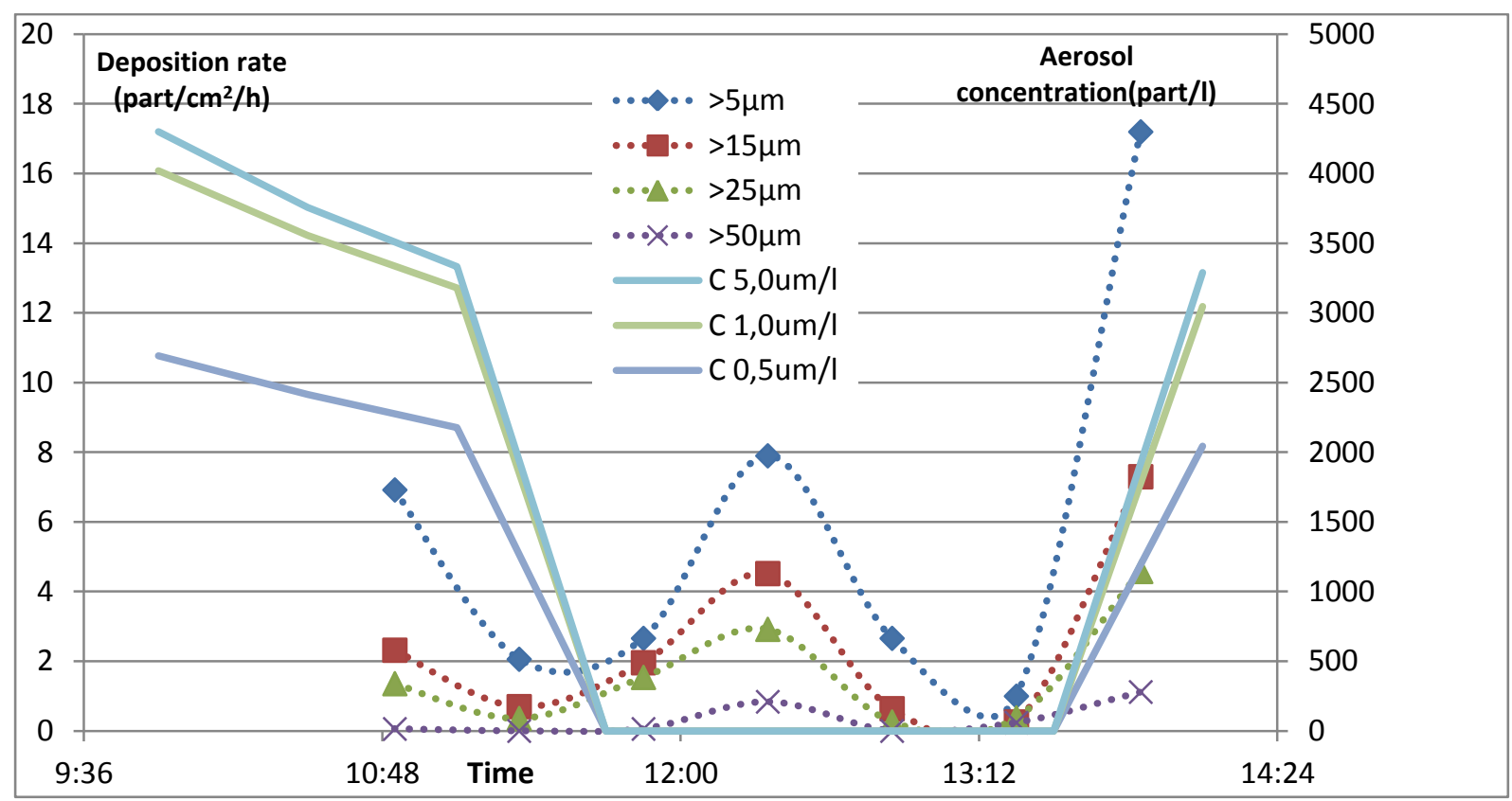

Figure 9. Aerosol results compared to deposition rate given by the CLEAPART-100 in the office over 4 hours

\section{Conclusion}

In the cleanroom environment used for these tests, the number of particles collected by the CLEAPART-100 was consistent with the number detected by the deposition targets (i.e. close to 0 for all size categories). CLEAPART-100 and the optical counter detect the same contamination event in such a clean environment.

In conditions with substantial quantities of dust (e.g. an office), once again, the CLEAPART100 detects the same contamination events as the optical counter.

In these non-classified dusty conditions, comparison of the real-time results recorded by the CLEAPART-100 with those from two deposition targets shows us the influence of the chemical make-up of the deposition target on the number of particles counted (i.e. the number of particles collected, or at least the number which remained stuck to the surface during transportation to the optical microscope in ISO 5 conditions). Glass appears to be a more suitable medium than the polycarbonate membranes, which may underestimate by an order of magnitude the number of particles higher than $5 \mu \mathrm{m}$ collected on the glass slides (bearing in mind that the collection plate of the CLEAPART-100 is made of glass too).

Direct collection of the particles collected by the CLEAPART-100, retrieved using gels, allowed us to confirm that a certain number of particles were lost during transportation of the deposition targets to the laboratory for counting. We thus demonstrated that the real-time results obtained, using the CLEAPART-100, are very similar to those obtained under an optical microscope using collection gels.

During this series of tests, the advantages of the CLEAPART-100 system became clear to see. As we have seen, the deposition targets underestimate by a factor higher than 10 the actual number of particles deposited (due to the loss of particles during transportation to the optical microscope, but also as a result of the nature of the substrate itself). We also developed a method allowing us to compare the performance of the CLEAPART-100 with that of an optical microscope combined with a leading image analysis system (Ellix, by Microvision), 
with the help of gels to collect particles directly onto the glass surface of the CLEAPART100. This method allows us to qualify the performance of the CLEAPART-100.

Considering the high risk occurring from particles larger than $5 \mu \mathrm{m}$ in many industries (optics, lasers, space, automobile, pharmaceuticals, medical devices etc.), we recommend using the CLEAPART-100 to supplement the optical counters generally used in cleanrooms. For those industries, the particle contamination risk is above all linked to the number of macroparticles larger than $5 \mu \mathrm{m}$ deposited on surface and not to the aerosol concentration.

\section{Acknowledgements}

We would like to thank Mr. Devez from Microvision, who contributed to the analysis of the gels using an optical microscope and the ELLIX analytical software, and whose expertise helped to confirm our analysis.

\section{References}

[1] Peter SM. Particle Fallout in a Class 100,000 High-Bay Aerospace Cleanroom. Journal of IES 38.2 (1995) 15- 17.

[2] Pui DYH, Ye Y and Lui BYH. Experimental study of particle deposition in semiconductor wafers. Aerosol Science and Technology, 122, (1990) 795-804.

[3] Wu JJ, Miller RJ, Cooper DW, Flynn JF, Delson DJ and Teagle RF. Deposition of submicron aerosol particles during integrated circuit manufacturing: experiments. The Journal of Environmental Sciences, January/February, (1989), pp.27-28 and 43-45.

[4] Reul, R. P., et al., "A Forecasting Technique for Accumulated Particulate Contamination of Spacecraft Assemblies," TRW Technical Report 82078A, 30 Oct. 1970.

[5] Schneider, H. W., "Evaluation of Particulate Contamination for Unmanned Spacecraft Prelaunch Operations," J. Envir. Sci., Jan/Feb, 1975, p. 29.

[6] Stratmann F, Fisson H and Peterson TW. Particle Deposition onto a Flat Surface from a Point Particle Source, Journal of IES 31.1 (1988) 39-41.

[7] Hamberg, 0., "Particulate Fallout Predictions for Clean Rooms,"J. Envir. Sai., XXV(3), May/June, 1982, p. 15.

[8] Liu BYH and Ahn K Particle deposition on semiconductor wafers. Aerosol Science and Technology, 6(1987) 215-224.

[9] Hamberg O and Shon E.M (1984). "Particle size distribution on Surfaces in Cleanrooms," Aerospace Corporation, Report SD-TR-84-43, El Segundo and Proc of IES 1984, p14-19. 
[10] ECSS-Q-ST-70-50C, Particles contamination monitoring for spacecraft systems and cleanrooms, Oct.2011

[11] ISO 14644-3 (2005), Cleanrooms and associated controlled environments - Part 3: Test methods

[12] Agricola K, Practical experiences in practical deposition monitoring. Clean Air and Containment Review (2015), Issue 21, pp.4-8.

[13] Agricola K. Real-time Particle Deposition Monitoring of Operational Cleanroom Quality, Journal of the IEST, V.59.1 (2016) 1-13.

[14] ISO 14644-1 (2015), Cleanrooms and associated controlled environments - Part 1: Classification of air cleanliness by particle concentration

[15] Tovena Pecault, I., Pasquinelli M. Aerosol and deposited particle measurements in Laser MegaJoule, European Aerosol Congress, Milan Sept.2015

[16] Patent FR 1550614 (2015), Process and methods for detecting surface contamination by free airborne particles 